\title{
Managing a service: from two boxes to today
}

\author{
Sarah Dunn
}

\section{Introduction}

Since 1974, when family planning services were taken over from local authorities and the Family Planning Association by the National Health Service (NHS), one thing has been certain: organisational change. Since 2001, the National Strategy for Sexual Health and HIV ${ }^{1}$ has been the focus for improving sexual health. The Medical Foundation for AIDS and Sexual Health has developed recommended standards for all NHS-funded sexual health services to support the aims of the National Strategy. ${ }^{2}$

Wolverhampton is situated 13 miles northwest of Birmingham, England's second city. It is a densely populated, urban and suburban, mixed residential and industrial area. The industrial base was devastated in the early 1980s by a depression that continues to affect parts of the West Midlands conurbation. The southeast and northeast areas of the city have a high index of deprivation, whereas the southwest area is more affluent. The population is diverse, and includes a significant ethnic minority population including asylum seekers and economic migrants. The University of Wolverhampton has several sites across the city and in nearby towns. The student population overall reached 23908 in 2003-2004 and there are many international students. The Contraception and Sexual Health (CASH) Service provides a citywide service to the population of 236000 .

Wolverhampton has high conception rates. In 2003, the rate among 15-17-year-olds was 56.2 per 1000 female population, of which $48.3 \%$ of conceptions led to abortion. ${ }^{3}$ In comparison, the average rate of conceptions for the West Midlands region was 47.2 per 1000 in this age group. As a result of initiatives funded through the Teenage Pregnancy Strategy of 1999, Wolverhampton's conception rates have shown a downward trend since 1998, when comparable rates were 66.3 per 1000 female population. Within Wolverhampton the areas of significant deprivation in the southeast and northeast of the city, which coincide with the high rates of teen pregnancy, benefit from governmentfunded Sure Start and Sure Start Plus projects.

\section{Organisation}

Wolverhampton City Primary Care Trust (PCT) was formed in 2002 and commissions primary care services from 127 general practitioners (GPs) working from 65 general practice premises and acute hospital services from the Royal Wolverhampton Hospitals NHS Trust. The Contraception and Sexual Health Service currently resides in the Children's Directorate of the provider arm of Wolverhampton City PCT.

J Fam Plann Reprod Health Care 2006; 32(2): 116-118

(Accepted 13 February 2006)

Contraception and Sexual Health Service, Wolverhampton City PCT, Wolverhampton, UK

Sarah Dunn, FFFP, MRCGP, Lead Associate Specialist

Correspondence to: Dr Sarah Dunn, Contraception and Sexual Health Service, 26a Snow Hill, Wolverhampton WV2 4AD, UK. Tel: +44 (0) 1902 444451. Fax: +44 (0) 1902444449.

E-mail: Sarah.Dunn@wolvespct.nhs.uk
The Contraception and Sexual Health (CASH) Service In 1992, I was appointed to the post of 'Medical Manager' of Wolverhampton Health Authority's Family Planning Service. My predecessor was a consultant in public health who was the part-time medical manager of the Family Planning Service. The only preparation for my future role was an inheritance of two boxes of my predecessor's old papers. Initially, my job consisted of one clinic a week and half a session for administration and audit, whilst I continued to work as a GP on a part-time basis.

In 1993, the service was largely organised and run by the support services manager and the lead nurse, at a time when NHS bureaucracy had not reached the levels we have to contend with today. Things changed when, in 1997, I decided to leave my role as a principal in general practice and was appointed as lead senior clinical medical officer for the renamed Contraception and Sexual Health Service. My first priority was to acquire skills in genitourinary medicine (GUM) by taking up a 6-month clinical attachment at Wolverhampton's GUM clinic. I have been doing a weekly clinic on the female side, which gives me an opportunity to maintain my skills and follow through women who attend both sexual health clinics - perhaps the beginning of a more holistic and 'joined-up' sexual health service.

\section{Relocation}

In 1996, the Family Planning Service was renamed the Contraception and Sexual Health Service and relocated. We moved from a shared health centre to dedicated premises in the town centre. The converted ground floor shop front houses a reception/office, two small consulting rooms and a waiting room. Upstairs, we have four clinical consulting rooms, a pregnancy counselling office and our administration suite. Our facilities are less than ideal for patients and staff, with a split-level layout that is inconvenient for everyone. There are separate commercial offices on the second floor.

This move necessitated reduction of our peripheral clinics, as the budget was not enhanced. Many staff members were unhappy with the reduction to four outreach clinics. The Directorate manager drove the project forward whilst the lead nurse, the support services manager and myself put up some resistance. Whilst this is a normal reaction to change, it is now most likely that I will be the one to deliver unwelcome news!

Another example of change management was the introduction in 1999 of chlamydia screening prior to intrauterine device (IUD) insertion, as a result of a critical incident review.

When problems have to be confronted, involving staff in the process has proved to be invaluable. Every member of staff should be encouraged to contribute to the debate and to help reach solutions. This cuts down the time taken to tackle all aspects of the problem. Some people are reluctant to take part, and providing such individuals with support is crucial. Group meetings can be very effective, preferably when there is a clear focus on the task, with action planning to facilitate the process. If a consistent message is repeated and people have the chance to be involved in the decision-making process then their support is usually assured. Nevertheless it may, of course, be some time before a staff member will admit that a newly introduced procedure is an acceptable change. 


\section{Clinics and service delivery}

This is made up of five services: Contraception, Cytology, Pregnancy Assessment Clinics, Psychosexual Counselling and the HIV Community Nursing Service. In 2004-2005, 16764 contacts attended Contraception Services, 1113 attended the Pregnancy Assessment Service, 411 attended the Cytology Service and 187 the Psychosexual Counselling Service. The whole CASH Service is currently run by six doctors [1.80 whole-time equivalent (WTE)]; 16 nurses (4.60 WTE) and 13 administrative and clerical staff (6.40 WTE)

\section{Contraception}

The highest numbers of clients attend the 20 or so contraception clinics. Most of these are located at the centrally situated Snow Hill Centre, open all day and into the evening for appointments, or drop-in clinics, open Monday to Friday. At the outreach sites, there are two clinics in the southeast area, one in the southwest and another in the northeast area. There is also a youth clinic, set up with Health Action Zone (HAZ) funding, in a dedicated Young Persons Service in the town centre on Saturday afternoons. Two dedicated youth clinics are run at Snow Hill Centre, and these are our most popular times.

Despite the physical disadvantages of the building, having our base at Snow Hill has proved successful in allowing us to develop services more effectively. We provide all methods of contraception and carry out free early detection pregnancy tests. A patient group direction (PGD) for emergency contraception was developed for nurses and community pharmacists and went live in December 2001. This has proved effective at improving the availability of progestogen-only emergency contraception. All six doctors fit IUDs/the intrauterine system (IUS), five of us fit and remove the implant, and five of us are Faculty Instructing Doctors. Our lead nurse is a trained natural family planning counsellor.

\section{Nursing issues in contraception}

In 2004, the new lead nurse (clinical nurse specialist) volunteered to train in IUD/IUS and Implanon ${ }^{\circledR}$ fitting and removal and she attended the Royal College of Nursing $(\mathrm{RCN})$ theoretical training days. All the instructing doctors contributed to her clinical training, leading to her subsequent accreditation by the RCN. She now provides the service and the clients with more flexibility and choice of provider in the clinical services we offer. There is increasing difficulty in recruiting doctors under current financial circumstances, at a time of enhanced GP remuneration. This development has proved to be an effective and welcome addition to manage the increased demand for IUDs/implants in respect of our clinics' lengthening waiting times.

The PCT clinical governance lead was anxious that suitable arrangements for training and ongoing clinical supervision would be available. This has been addressed by keeping a $\log$ of clinical activities, providing opportunities for reflective practice, case discussions and clinical supervision both on an ad hoc basis and at regular intervals.

Agenda for Change grading decisions have been successful for former E and F Grade nurses, but not so for the three former $\mathrm{H}$ Grade clinical nurse specialists in the Service whose appeals have been lodged.

PGDs have been developed for combined oral contraceptives, progestogen-only pills, contraceptive patches, Depo-Provera ${ }^{\circledR}$ injections, emergency hormonal contraception and doxycycline for pre-termination patients and for treatment of positive chlamydia in non-pregnant women. These have now been signed off, after a long wait for ratification.

\section{Cytology Clinic}

This clinic is now nurse-led, having formerly been staffed by a doctor. It alternates between Snow Hill Centre, twice a month, and once a month at two of the peripheral clinics. About 400 clients a year are seen for cytology. Recently, the colposcopy clinic at the hospital has introduced direct referral for women with abnormal smears, which has cut down the waiting time between diagnosis and treatment.

\section{Pregnancy Assessment Clinic}

This service, which aims to provide a medical assessment service for pre-termination of pregnancy patients, has been in existence at the CASH Service since the early 1980s.

In 2002, targets to improve access to abortions were introduced. Our performance on waiting times was found to be unsatisfactory, and the percentage of terminations carried out before 10 weeks was also poor: we were once again in trouble. We began a painful process of changing practices within the service by introducing nurse-led clinics, employing more clerical staff and accepting selfreferrals. This resulted in a significant increase in the proportion of NHS-funded abortions performed under 10 weeks from $35 \%$ in 2003 to $52 \%$ in 2004 and was the highest percentage in the Birmingham and Black Country Strategic Health Authority area.

In 1998, in collaboration with the GUM consultants, we produced a patient care pathway for management of chlamydia infections for women seeking abortion. We changed to the strategy of universal screening and antibiotic prophylaxis, which was later recommended in the Royal College of Obstetricians and Gynaecologists' National Audit of Induced Abortion (2000). ${ }^{4}$

My GUM colleagues supported me in obtaining supplies of a small formulary of antibiotics for treating infections identified from pre-termination swabs. Doxycycline, azithromycin, metronidazole, erythromycin and clotrimazole pessaries and cream were stocked. The microbiology department consultants responded to our new arrangements as we had shared clinical meetings, which highlighted the need to reduce the risk of long-term complications from untreated chlamydia. The duty microbiology consultant phones through positive chlamydia results within 48 hours. We can inform the patients, having ensured that contact arrangements have been arranged, and treat them with azithromycin $1 \mathrm{~g}$ oral stat, preoperatively, where possible and appropriate. We use a sexual history format that was developed to standardise the screening questions and identify risks. We inform patients of diagnoses and manage them according to national guidelines. All patients with positive sexually transmitted infection (STI) diagnoses are referred to the GUM clinic with a standard letter that we fax to their 'Safe Haven' fax. Moving the two sexual health services closer is a gradual process, the clinical care pathways being a first step in this process.

\section{Psychosexual Counselling}

A psychosexual nurse therapist (British Association of Sexual and Relationship Therapists trained) now runs this clinic following staff changes. Previously this clinic was staffed by an Institute of Psychosexual Medicine-trained doctor. The West Midlands seems to be a place where psychosexual counselling services are difficult to find. Waiting lists are long and high rates of non-attendance are an inevitable result of this challenging work. 


\section{SERVICE DELIVERY}

\section{HIV Community Nursing Service}

Two male $\mathrm{H}$ grade clinical nurse specialists staff this service. They care for HIV-positive patients in Wolverhampton, and they have created an excellent service for their clients. They also teach at the University of Wolverhampton. There is a men-only clinic on Wednesday evenings, for STI screening and HIV testing, staffed by male workers. A successful 'Black Barber Shop' scheme was started some years ago, by Black HIV and minority ethnic specialist nurses. The aim of service was to disseminate sexual health literature and condoms via the Black Barbers to groups of men who are traditionally hard to reach. The scheme has been highly successful and was recognised as an example of good practice by the Department of Health in Liberating the Talents: Helping Primary Care Trusts and Nurses to Deliver the NHS Plan. 5 The clinical nurse specialists also offer a HIV testing service from the Terence Higgins Trust building on Saturday mornings.

\section{Wolverhampton's Teenage Pregnancy Unit}

This service has several work streams. They include a growing network of sex and relationships education workers who support local schools in delivering relevant education around sexual health. In the Prevention Team a G Grade sexual health development worker has set up eight 'Health Point' Outreach Clinics within targeted youth venues. Pregnancy advisers provide support to those individuals considering pregnancy choices and provide support to teenagers facing termination of pregnancy without parental support. The CASH Service and others refer to the Teenage Pregnancy Unit pregnant teenagers who need support in continuing their pregnancies. A female consultant obstetrician runs a Teenagers' Antenatal Clinic, supported by a dedicated team of midwife, youth worker and the sexual health development worker. The aim is to reduce the number of repeat pregnancies. There are local housing projects rolling out for teenage mothers who have accommodation problems

\section{Reflections}

Changes have sometimes had to be reactive to external situations out of our control. Government targets or performance ratings influence the priorities, and these have certainly brought resistance to change. In a small service with experienced staff it can be challenging to be perceived as being on the side of 'management' with colleagues you have known and liked for more than 10 years. However, with time, new initiatives don't seem so bad. In some ways, a small service is much like a family, where people can have a good laugh, support each other in a crisis, and have 'moods' at times.

The National Strategy for Sexual Health and HIV ${ }^{1}$ has prompted a focus on the necessary training for primary care in contraception as well as sexual health. The teaching role of the clinic is essential for providing future clinicians and for improving the knowledge, skills and attitudes to provide better care for patients.

\section{The future}

We are beginning to build closer links with local GPs by way of improving understanding between CASH and the GPs regarding local service provision. Since the introduction of the new General Medial Services (GMS) contract in 2004, we need to understand what services around sexual health local GPs offer (i.e. contraceptive, IUD and sexual health services). A learning needs analysis to inform what training is required will help us to provide suitable courses that are fit for purpose, for those individuals who wish to become providers.

Chlamydia screening using modern methods of testing will be welcomed, as our enzyme immunoassay tests recently produced more equivocal results than ever before! Every time I do a Youth Clinic, I think of all those teenagers declaring unprotected sexual intercourse who need non-invasive chlamydia testing. We look forward to the time when we can start on the National Chlamydia Screening Programme.

Our new computer software purchase is due in the next few months, and this should streamline many operations, including printing labels. This may challenge those who dislike technology!

Agenda for Change is nearly there, but key posts have not yet been assimilated. Nurse-led services are coming inevitably; but as I write this, we are so short of nurses and doctors that the staffing crisis is high on our agenda.

The arrival in July 2005 of a new consultant in public health, whose job is focused on her role as the PCT sexual health lead, is a welcome bonus to help the Sexual Health Services to get 'with it'. It is perhaps rare nowadays for a Public Health Consultant to combine jobs and lead a Contraception and Sexual Health Service.

Acknowledgements

The author wishes to acknowledge the assistance provided by Drs Rufus Fernando, Taha Wanas, Chris Catchpole, Mike Cooper, Donald Dobie, Helen Sullivan, Gill Wakley and Louise Massey, with Wendy Moore, Joseph McLean and all the staff at Snow Hill Centre, Wolverhampton City PCT.

References

1 Department of Health. The National Strategy for Sexual Health and HIV. London, UK: Department of Health, 2001.

2 Medical Foundation for AIDS and Sexual Health (MedFASH). Recommended Standards for Sexual Health Services. London, UK: Department of Health, 2005

3 Office for National Statistics and Teenage Pregnancy Unit. Under 18 Conceptions Data for Top-tier Local Authorities (LAD1), 1998-2003. London, UK: Teenage Pregnancy Unit, 2005. http://www.dfes. gov.uk/teenagepregnancy [Accessed 1 November 2005].

4 Royal College of Obstetricians and Gynaecologists (RCOG) Clinical Effectiveness Support Unit. National Audit of Induced Abortion 2000: Report of England and Wales. London, UK: RCOG Press, 2001. http://www.rcog.org.uk/resources/public/pdf/nataudit_iabortion_ 2000.pdf [Accessed 1 November 2005].

5 Department of Health. Liberating the Talents: Helping Primary Care Trust and Nurses to Deliver the NHS Plan. London, UK: Department of Health, 2003; 29.
The latest version of the Journal's Notes for Contributors can be found on the Faculty website at www.ffprhc.org.uk. The electronic notes are reviewed regularly and updated as required. 